\title{
Artificial Seeding Effects of Convective Clouds on the Opening Day of Beijing 2008 Summer Olympics
}

\author{
Hongyu Li', Yanping Dai ${ }^{*}$, Hua Wang², Jingang Cui ${ }^{3}$ \\ ${ }^{1}$ Weather Modification Center, Chinese Academy of Meteorological Sciences, Beijing, China \\ ${ }^{2}$ Environment Meteorology Forecast Center of Beijing-Tianjin-Hebei, China Meteorological Administration, Beijing, China \\ ${ }^{3}$ Baodi District Weather Modification Office, Tianjin, China \\ Email: *daiyp@camscma.cn
}

How to cite this paper: Li, H.Y., Dai, Y.P., Wang, H. and Cui, J.G. (2017) Artificial Seeding Effects of Convective Clouds on the Opening Day of Beijing 2008 Summer Olympics. Journal of Geoscience and Environment Protection, 5, 118-138.

https://doi.org/10.4236/gep.2017.54010

Received: December 30, 2016

Accepted: April 24, 2017

Published: April 25, 2017

Copyright $\odot 2017$ by authors and Scientific Research Publishing Inc. This work is licensed under the Creative Commons Attribution International License (CC BY 4.0).

http://creativecommons.org/licenses/by/4.0/

\begin{abstract}
Using the radar reflectivity and intensive rainfall data, artificial seeding effects of convective clouds in Beijing on 8 August 2008, the opening day of the 29th Summer Olympics, were analyzed. The results indicate that, cloud seeding at single operation site for convective clouds invading from southwest direction may sharply mitigate the rainfall observed at leeward automatic weather stations within 5 - $10 \mathrm{~min}$, while enhances the precipitation at a later stage about 10 - 20 min. Cloud seeding effects of operation sites Yuegezhuangxi, Changgouzhen, and Zhoukou, which are placed along the main moving routes or localized developing convective clouds in the west and center parts of Fangshan district, are very conspicuous. Combining the operation sites distribution and radar echoes, it is found that the site Changgouzhen, which is very close to the convective core, plays an essential role in suppressing the growth of convective cloud, reducing the coverage area of intense echoes classified as $45-60 \mathrm{dBZ}$, as well as mitigating the precipitation from neighboring automatic weather stations. Based on radar reflectivity and rainfall data, we find that the clouds over lots of operation sites in eastern Fangshan district are not cold enough to favor glaciogenic seeding with silver iodide, meanwhile, there is not too much precipitation observed.
\end{abstract}

\section{Keywords}

Cloud Seeding, Convective Clouds, Olympics

\section{Introduction}

It is possible to influence local precipitation through artificial seeding: a small amount of catalysts or stirring dynamical impacts inside clouds, and sometimes 
even get some obvious effects under favorable conditions (Schaefer [1]; Huang et al. [2]; Lei et al. [3]). Cloud seeding can not only increase precipitation, but also suppress the development of clouds and precipitation in a target area, which is usually called "precipitation redistribution" or "rain mitigation" and is an extension of weather modification technology. Rain mitigation is mainly employed to provide better weather for open-air activities in big cities, for instance, the opening or closing ceremony of large-scaled outdoor sport games, art festivals, celebration activities, etc. Based on the basic approach of static seeding or dynamic seeding in the upwind of focused zone, the formation and growth of seeded clouds and precipitation can be influenced, thus, the protected zone will be less rainfall or even no rainfall at all, where the weather is improved well to actual demands (Zhang et al. [4]). As an important part of public meteorological service, the rain mitigation technology has caught the great attention because of its enormous social benefits generated.

Since a long time, scientists have been attempting to carry out various experiments on artificial dissipation of clouds and rain, intercepting rainfall in the windward side, and artificial suppression of local heavy rain, for instance, Ye [5]; Li et al. [6], etc. Especially in former Soviet Union, scientists gained much more successful examples and some feasible technical indexes were concluded from lots of experiments. In the 80 s, a set of techniques on artificial precipitation reduction or inhibition of the development of convective clouds has been refined, based on theoretical research and experiments. Such technology played an important role in preventing the spread of nuclear pollution emission from the accident at the Chernobyl nuclear power plant in 1986. At present, abroad artificial rain mitigation and convective cloud inhibition (mainly in Russia) are mainly applied for weather protection during special festivals \& events such as parades at the Red Square on the anniversary of Victory Day on 9 May in Moscow, Moscow City day celebrations, anniversary of the day when the St. Petersburg city was established, and provide special services like snow clearing at cities and towns in winter (Bedritsky and Chernikov [7]; Petrov et al. [8]; Korneev et al. [9]; Koloskov et al. [10]; Petrov et al. [11]). This technology is commonly employed by the government and public sectors, and also taken as a substantial measure for the Russian Ministry of Emergency Situations.

In China, artificial rain mitigation technique is developing just at a trial stage. As one of the emergency support measures for significant activities, some domestic provinces and cities used to perform several operational experiments at the service request. According to Li et al. [6], various cloud or rain mitigation activities have been carried out to the service need of meteorological support, such as the Beijing $35^{\text {th }}$ and $50^{\text {th }}$ National Day's parade in 1984 and 1999 respectively, opening ceremonies of Kunming World Horticultural Exposition Garden in 1999, opening ceremonies of Nanjing 10th National Games in 2005 and Wuhan $6^{\text {th }}$ National City Games in 2007. Based on these attempts, preliminary organization experience was learnt, but there is still lack of technical accumulation. In general, the existing literature on artificial rain mitigation is extremely li- 
mited, though the application of such techniques has already been propelled.

According to Zhu et al. [12], the predominant weather systems during the period of the Beijing 2008 Summer Olympic Games are complex and changeable, and the probability of severe weathers such as vigorous convection and heavy storms is much higher, since it enters the midsummer and the main flood season in North China. To prevent rain from dampening the opening ceremony and provide best meteorological service, Beijing meteorological departments have carried out relevant research on artificial rain mitigation and conducted several scientific experiments on different types of clouds and precipitation since 2002. We also learnt some advanced technology and experience from Russians through bilateral cooperation. On 8 August 2008, the opening day of the Olympic Games, Beijing organized a large-scaled artificial rain mitigation operation in the west and southwest to avoid probable impact of raining to the National Stadium. The organization and implementation of the operation has been described in detail by Zhang et al. [13] [14], but technical analysis on this unique weather modification activity is very limited (Li et al. [15]; He and Ma [16]; Li et al. [17]; He et al. [18]). In the present paper, the authors try to reveal the physical response by further analyzing the convective cloud seeding processes, and by combining the ground-based cloud seeding information with the rainfall and radar reflectivity data which both have a relatively higher spatial and temporal resolution.

\section{Observation Data and Method}

\subsection{Precipitation of Automatic Weather Station}

As a major part of domestic meteorological observation network, data from automatic weather stations (AWS) own several advantages, such as higher accuracy and precision, fine spatial and temporal resolution, etc. Up to August 2008, 187 automatic meteorological stations had been established throughout Beijing city. Among them in Figure 1, there were 168 intensified stations, 88 stations can observe six elements including temperature, humidity, surface pressure, wind direction, wind speed, and precipitation; 45 stations for four elements including temperature, wind direction, wind speed, precipitation; 27 stations for temperature and precipitation only, and another 8 stations can observe more than 6 elements. The average distance of stations is about $5 \mathrm{~km}$. The spacing in suburb and mountain areas is larger than that in city zones. Minimum sampling interval is 1 minute. Precipitation information in 5-minute interval can be provided in time, and data observed at such temporal and spatial scale can meet the basic need of regional meso and small scaled weather monitoring.

Under similar topographical conditions, the observation and tracking of precipitation zones from AWS data during continuous weather processes in relative fixed moving direction can indicate clearly the occurrence and development of clouds along their moving routes. Some seeding effects on precipitation also can be identified by combining the 5- or 10-min accumulated precipitation data with detailed operation information. 


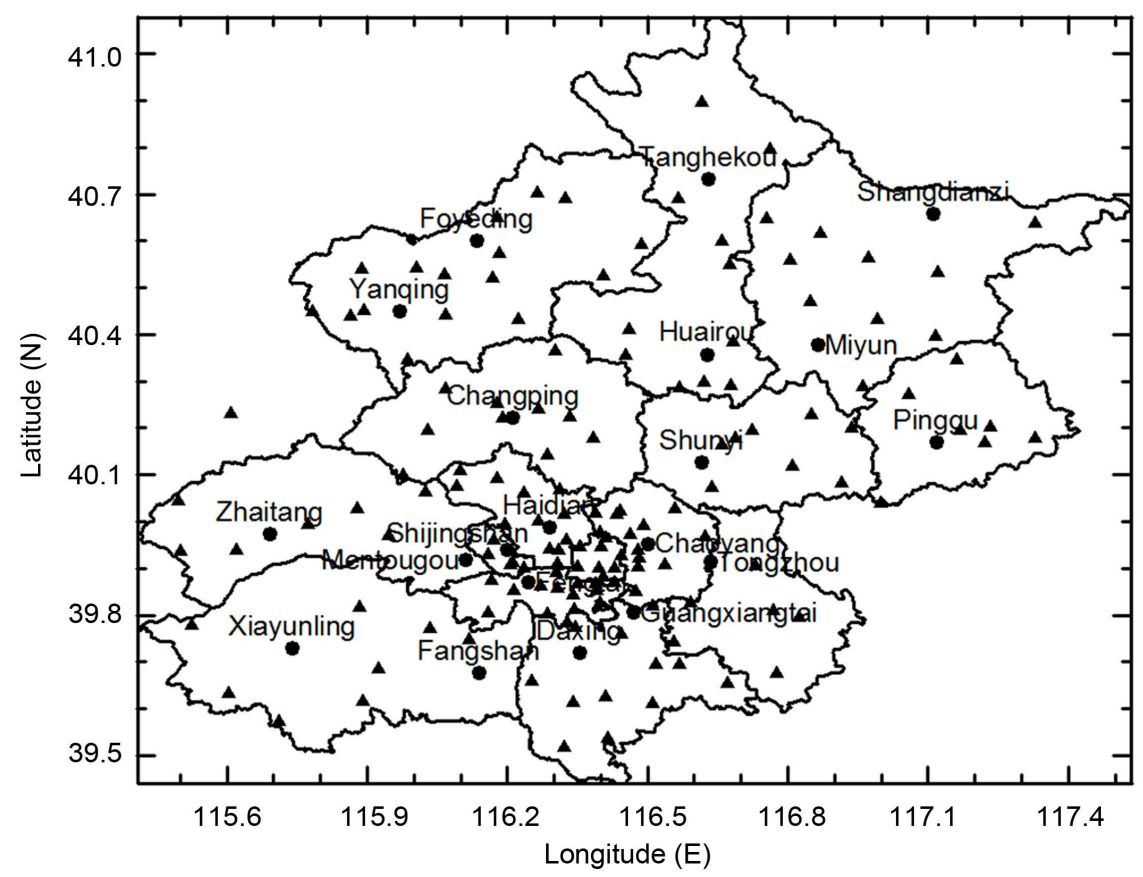

Figure 1. Distribution of the automatic weather stations in Beijing by the end of Aug. 2008 .

\subsection{Reflectivity of Doppler Weather Radar}

With a high spatial resolution, the doppler radar is able to capture those overwhelming meso and small scaled weather systems within its detection range. It acts as the core commanding mean for operational or experimental programs on weather modification, except that it provides monitoring and forecasting service for conventional and disastrous weather events. The fully coherent doppler weather radar operational system CINRAD/SA (New Generation Doppler Weather Radar, enhanced $\mathrm{S}$ band), which was established in the atmospheric observation base in southern suburb of Beijing city in 2006, is a joint production by Chinese Minshida Company and America Lockheed Martin Company. Its maximum detection range for reflectivity is $460 \mathrm{~km}$, and $230 \mathrm{~km}$ for doppler velocity. The finest resolution of reflectivity factor product is $1 \mathrm{~km}$. For precipitation weather observation, VCP21 is the prior mode selected; the volume scanning is completed at 9 elevation angles from $0.5^{\circ}$ to $19.5^{\circ}$ in just 6 minutes.

Among radar products, the reflectivity CAPPI (Constant Altitude Plan Position Indicator) can reflect distributions of particle size, number density within the meteorological targets at a certain level. The product CR (Composite Reflectivity) is the projection of maximum reflectivity within a volume scan to the cartesian grids. It helps to identify the overall strength of the targets and their structure characteristics. In this analysis, we investigate the evolution of radar echoes intensity and the position change of the echo core during the cloud lifetime and especially before and after the seeding time, through area statistics of classified radar reflectivity factors ( $\leq 15 \mathrm{dBZ}, 15-30 \mathrm{dBZ}, 30$ - $45 \mathrm{dBZ}, 45-60$ $\mathrm{dBZ}$ and $\geq 60 \mathrm{dBZ}$ ) at a level affected directly by seeding agents, a lower level 
closely related to surface precipitation and the composite reflectivity,. In addition, variation of surface precipitation amount within certain time and space range is also gained from radar estimated quantitative precipitation.

\section{Weather Background}

Influenced by integrated westerly trough, subtropical high over western Pacific and the typhoon in the south of high pressure, Beijing was in the periphery of subtropical high for a long time and warm humid air surges continuously in early August 2008. On 8 August, the subtropical high pressure weakened and backed to east. It began to rain early in the morning at some parts of Huairou and Miyun districts. Cloud and precipitation system which was originated in Hetao region is developing and gradually moving close to Beijing. In the afternoon, followed by eastern and northern stretch of the subtropical high, northwestern and southeastern Beijing were controlled by cold air and the shear line at $850 \mathrm{hPa}$ level respectively (Figure 2). The surface inverse trough was generated

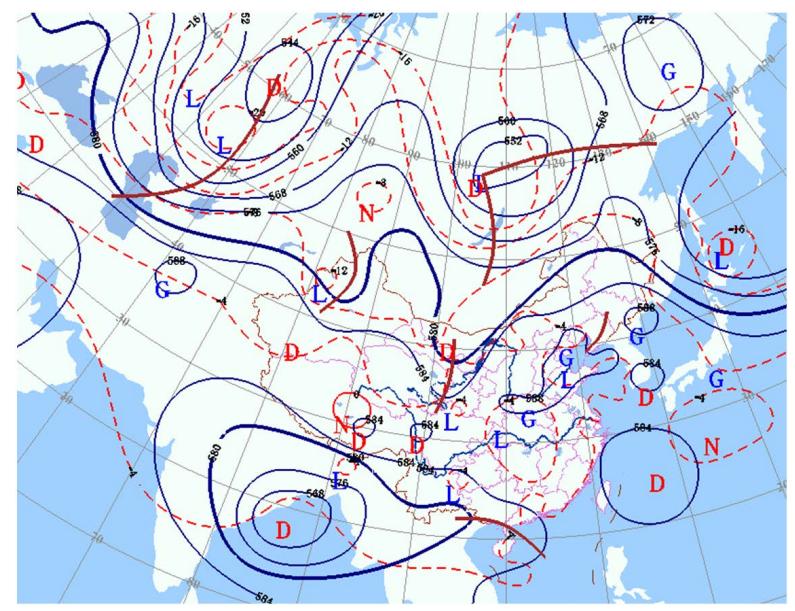

(a)

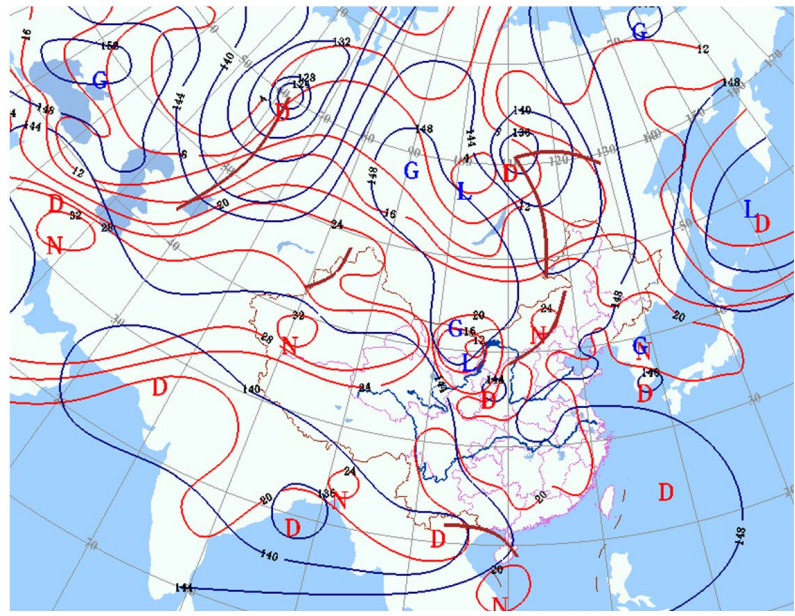

(b)

Figure 2. Location and intensity of the subtropical high displayed at $500 \mathrm{hPa}$ level (a), and location and effects of the convergence of warm and cold air and the shear line displayed at $850 \mathrm{hPa}$ level (b), at 2000 LST 8 Aug. 
and deepening gradually at the same time. Affected both by the shear line and surface inverse trough, there were systematic convection clouds developing in southwest Beijing and moving toward northeast. On the other hand, cold air in the northwest broke up continuously and moved to the east and south. Even worse, a conjunction of the northern and southern weather systems was likely to appear.

Before 2000 LST (Beijing Time, the same below), the punctual starting time of the opening ceremony, Beijing region just lied in the transition zone between the subtropical high and the westerly trough. Intensity and position of the two systems are quite stable (Dong et al. [19]). Till 2030, clouds and precipitation was coming from northeast and southwest cover Beijing suburbs. In Miyun district lightning occurs and scattered rain was even reported at Wukesong, a place very close to the National Stadium. Observation at 2135 displayed that vigorous convective clouds with a top height near $20 \mathrm{~km}$ appear in Baoding area, southwestern Hebei province, and the clouds were impending to Beijing. Strong convective clouds were developing in Beijing such as Mentougou, Shunyi, and Miyun districts.

\section{Details of Ground-Based Cloud Seeding}

Given the possible adverse effects of precipitation on the opening ceremony, several operation lines were designed and many operation sites were established around Beijing. Figure 3 displays the distribution of automatic weather stations and eleven tentative mobile rocket operation sites with their safe shooting ranges in Fangshan, a district southwest of Beijing. The right diagram shows flight and seeding trajectories of RYI-6300 type rockets shooting at various elevations. Each rocket contains 25 grams of silver iodide (AgI), with a nucleation rate of $1.0^{3} \times 10^{15}$ at minus 10 celsius. The specified shooting elevation is limited at 60 or 65 degree. According to the trajectory curve, the releasing height of AgI catalyst is between 4.6 and $5.7 \mathrm{~km}$. Based on the nearest sounding station, the level of zero celsius is approximately $5.1 \mathrm{~km}$ at 1400 on 8 August. At that level, the prevailing winds blew from southwest by west (WSW) with a direction about 250 degrees.

After 1608 on 8 August, operators began to seed convective clouds in the north, west and southwest according to about $20 \mathrm{dBZ}$ radar "first echo" (Rokicki and Young [20]) observations and direct commands from the decision-making department. Table 1 displayed detailed seeding information in the southwest, which was collected in Beijing Weather Modification Office. Among of it, operation site Yongdingheganqu (numbered S11) is omitted, since there is no seeding. We divide the seeding time into 9 stages, recorded from $T_{2}$ to $T_{7}$ respectively. Table 1 shows that, among the 10 operation sites in Fangshan, single site can launch a minimum of 6 rockets in 17 minutes $\left(\mathrm{T}_{5}\right)$ at one round seeding, while the maximum amount of 18 rockets in 12 minutes $\left(\mathrm{T}_{7}\right)$. In every round operation, the shortest seeding time lasts 6 minutes $\left(\mathrm{T}_{-2}\right)$ with 12 rockets launched, while the longest one lasts 18 minutes $\left(\mathrm{T}_{4}\right)$ with many sites launch 15 rockets. 
Contrast of operation amounts and the corresponding seeding time duration indicates different operation efficiency. It relates to the operator's technical proficiency, and on the other hand, the recorder unifies all sites' seeding time while they were authorized at the same round.

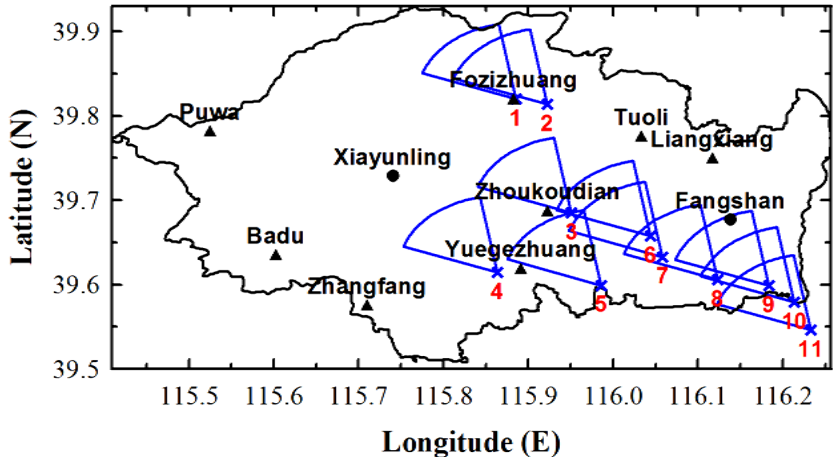

(a)

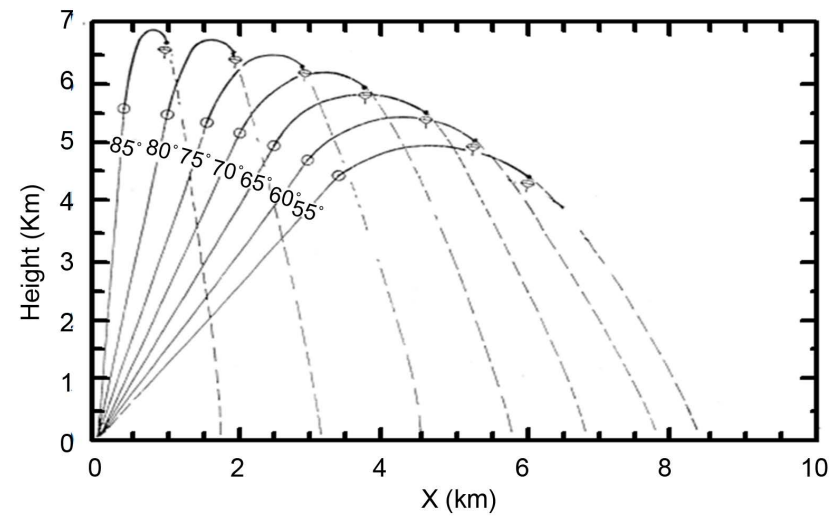

(a)

Figure 3. Distribution of automatic weather stations and the operation sites together with their effective range and trajectory curves for rocket seeding at different elevations.

Table 1. Detailed rocket seeding information including name, seeding time and seeding amount (rockets number) of each operation site in Fangshan district on 8 Aug.

\begin{tabular}{|c|c|c|c|c|c|c|c|c|c|c|}
\hline \multirow{2}{*}{\multicolumn{2}{|c|}{$\begin{array}{l}\text { Seeding time \& stage } \\
\text { site name \& No. }\end{array}$}} & \multirow{2}{*}{$\frac{1845-1851}{\mathrm{~T}_{-2}}$} & \multirow{2}{*}{$\frac{1859-1906}{\mathrm{~T}_{-1}}$} & \multirow{2}{*}{$\frac{2005-2012}{\mathrm{~T}_{1}}$} & \multirow{2}{*}{$\frac{2053-2105}{\mathrm{~T}_{2}}$} & \multirow{2}{*}{$\frac{2115-2125}{\mathrm{~T}_{3}}$} & \multirow{2}{*}{$\frac{2145-2203}{\mathrm{~T}_{4}}$} & \multirow{2}{*}{$\frac{2203-2220}{\mathrm{~T}_{5}}$} & \multirow{2}{*}{$\frac{2232-2245}{\mathrm{~T}_{6}}$} & \multirow{2}{*}{$\frac{2258-2310}{\mathrm{~T}_{7}}$} \\
\hline & & & & & & & & & & \\
\hline Fozizhuang & S1 & & & 9 & & & 15 & 15 & & \\
\hline Hebeizhen & S2 & & & 9 & & & 15 & 15 & & \\
\hline Changgouzhen & S3 & & & 9 & & 15 & 15 & 15 & 15 & \\
\hline Yuegezhuangxi & S4 & 12 & 12 & 9 & 15 & & 15 & 6 & & \\
\hline Zhoukou & S5 & & & 9 & & 15 & 15 & 15 & 15 & \\
\hline Shilouzhen & S6 & & & 9 & & & 15 & 12 & 15 & 18 \\
\hline Liulihe & S7 & & & 9 & & & 15 & 15 & 15 & 15 \\
\hline Nanzhaocun & S8 & & & 9 & & & 15 & 15 & 15 & 15 \\
\hline Yaoshang & S9 & & & 9 & & & 15 & 15 & 18 & 12 \\
\hline Yongdinghetan & S10 & & & 9 & & & 9 & 15 & 15 & 15 \\
\hline
\end{tabular}


In Table 1, the site S4 (Yuegezhuangxi), which is located in the far southwest and along the moving route of convective clouds, implements first round operation at 1845. With the impending of the clouds, other sites in Fangshan district carries out rocket seeding one after another. The operation time centers between 2053 and 2245. Totally 435 special rockets are launched in about two hours.

\section{Change of Precipitation}

\subsection{Precipitation Distribution}

According to AWS data, precipitation occurs in many districts including Yanqing, Changping, Fangshan, Mentougou, Haidian, Fengtai, Shijingshan, Huairou, Miyun and Daxing since the afternoon of 8 August. In the evening precipitable clouds coming from northeast and southwest influence Beijing suburbs gradually. Some areas, short-term heavy rain and lightning were observed. Figure 4 displays the 6-hour accumulated precipitation from 1800 to midnight. It is found that the precipitation was mainly distributed in the southwest (Fangshan) and north-northeast (Huairou and Miyun), while less precipitation was observed in city zones. A maximum precipitation over $40 \mathrm{~mm}$ was observed at Wengxizhuang station in Miyun. Compared with Miyun, rain in Fangshan occured a bit earlier, and a maximum rainfall of $15.2 \mathrm{~mm}$ was observed at Zhangfang station.

Distribution of 30-minute accumulated precipitation in Figure 5 displays that before 1800 few automatic weather stations in Yanqing and Mentougou districts observed scattered showers with rainfall about $0.1 \mathrm{~mm}$ in Beijing region. Then local convective clouds developed and enhanced in Fangshan, rainfall of $2.6 \mathrm{~mm}$ in 30 minutes was observed at Xiayunling station and the rain lasted a dozen minutes only. After 1900, convective clouds formed in southern Huairou district strengthen and followed by $8.6 \mathrm{~mm}$ rainfall in 30 minutes, thereafter, the clouds continued strengthening and moving slowly toward northeast to Miyun. Strong convective clouds coming from southwest gradually moved into Fangshan. At 2000, obvious rainfall was observed both in the southwest and north-northeast

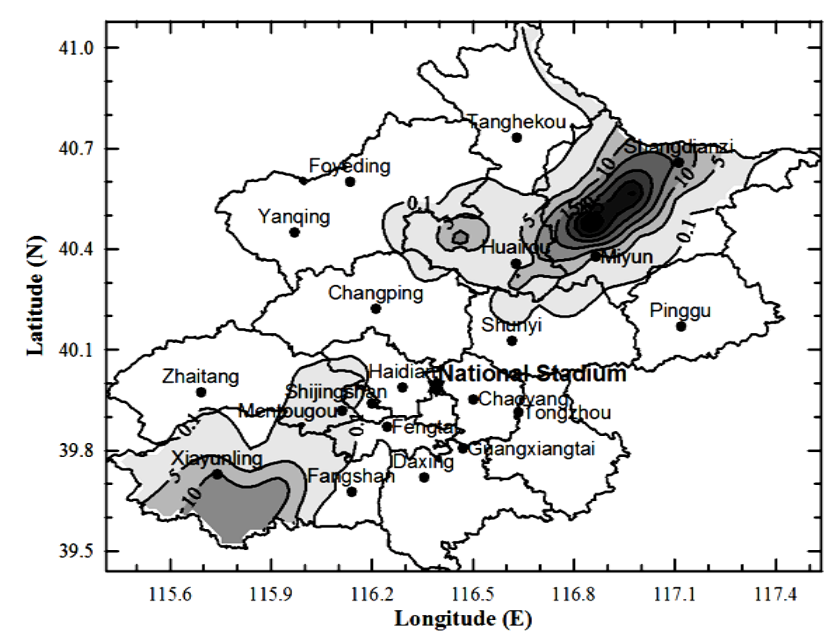

Figure 4. Distribution of 6-hour accumulated precipitation (unit in $\mathrm{mm}$ ) from 1800, 8 Aug. to 0000, 9 Aug. 


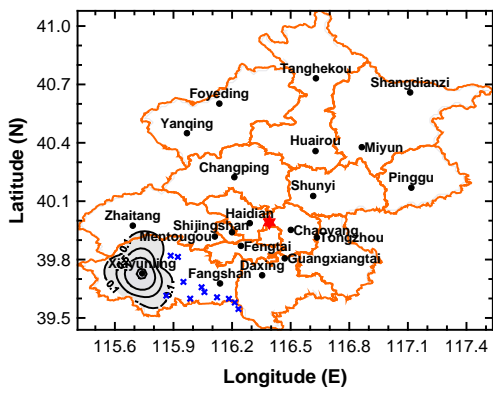

1830
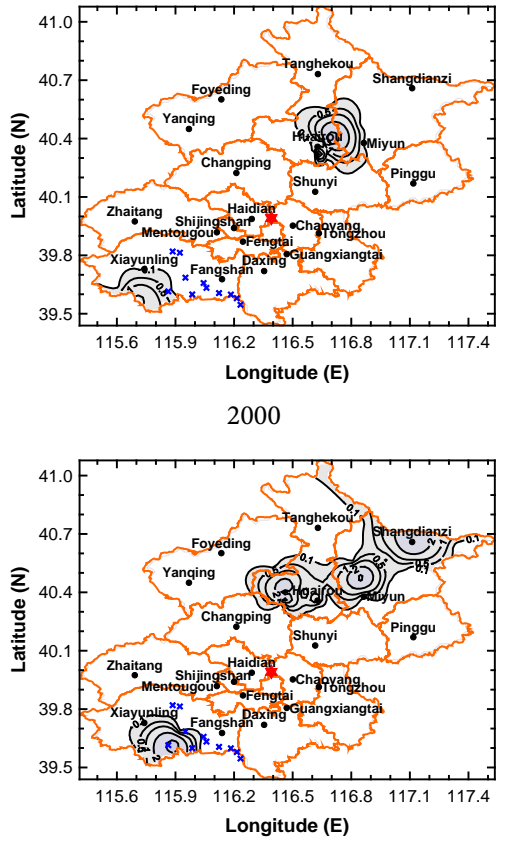

2130

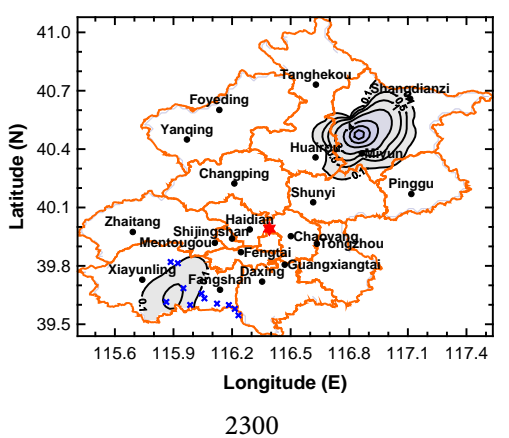

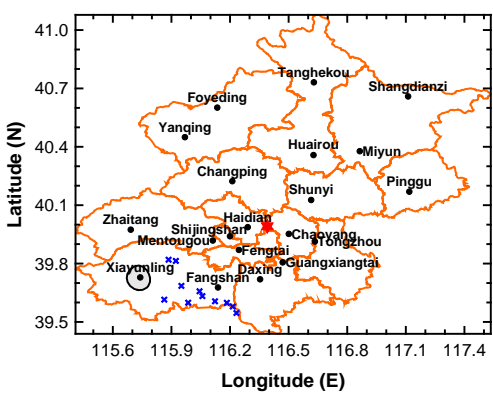

1900
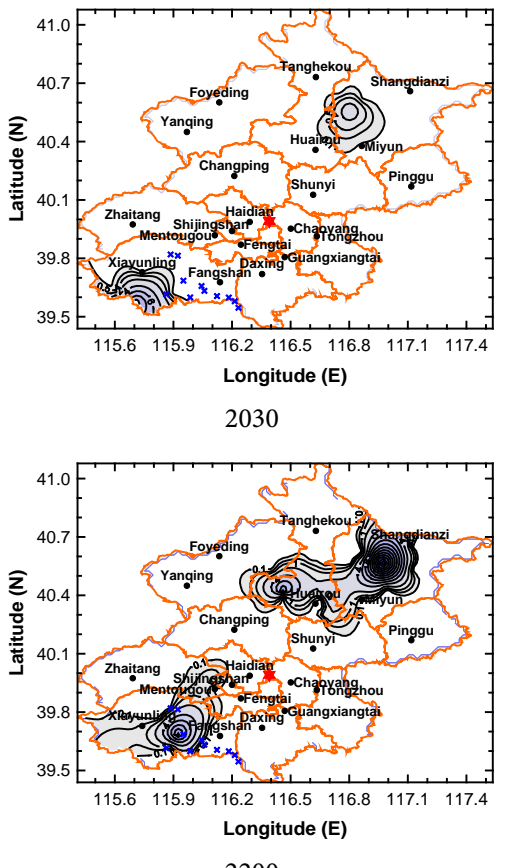

2200

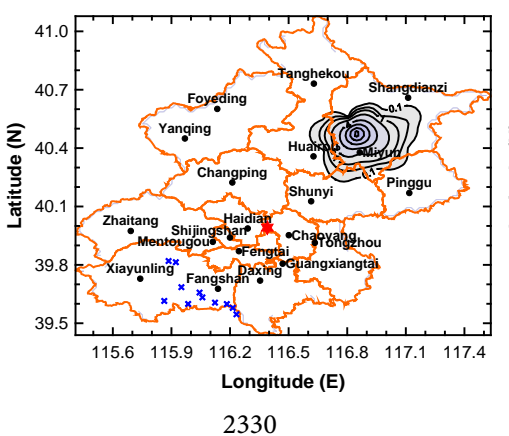

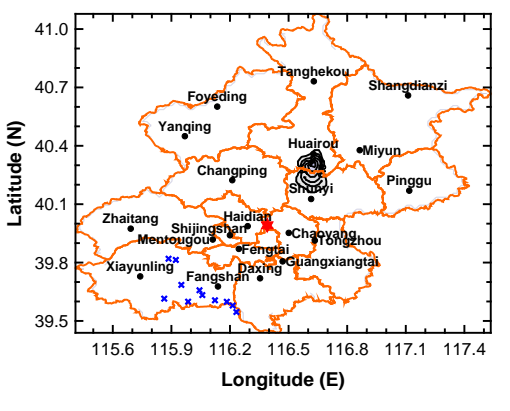

1930
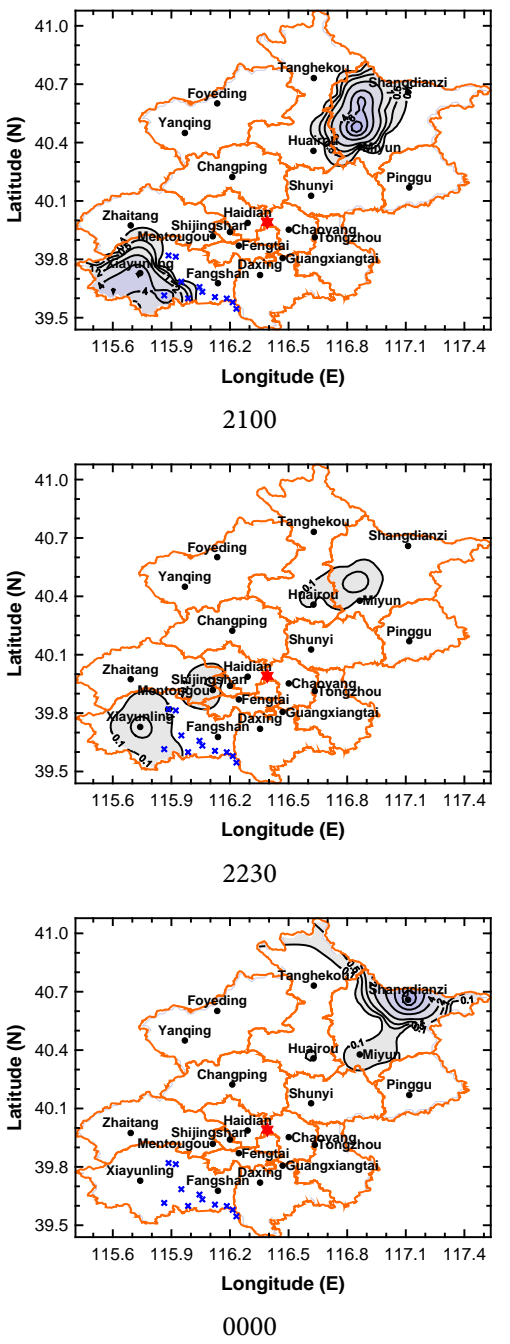

Figure 5. Time series of 30-mimute accumulated precipitation (unit in mm) from 1800, 8 Aug. to 0000, 9 Aug., together with operation sites (blue dot) in Fangshan.

of Beijing, At Wukesong, a place very close to the city zone, precipitation was also observed, and what is worse, convective clouds moving from southwest to northeast posed a great threat to the National Stadium.

Precipitation coming from southwest was mainly distributed in the west of Fangshan district before 2000. Combining with the rocket seeding information in Table 1, after the operation by the farthest site $\mathrm{S} 4$ at $\mathrm{T}_{-2}$ and $\mathrm{T}_{-1}$ time stages, no precipitation was observed near the site and its leeward side. As the clouds de- 
veloped, the 10 operation sites implemented $\mathrm{T}_{1}$ stage rocket seeding according to the rain reports by operators. Distribution of precipitation at 2030 and 2100 showed that the rain belt was extending to north, but in concentrated area of those operation sites there was rarely rainfall, and no precipitation was observed at lots of ground-based sites.

From 2100 to 2200, strong precipitation was observed all the time at the border of Miyun and Huairou. Multiple rain cores were gradually separated and extending to west and south. From 2100 to 2130 rainfall in the southwest mitigated and its northern branch contracted back. During this period, operation sites S4, $\mathrm{S} 3$ and $\mathrm{S} 5$ implemented $\mathrm{T}_{2}$ and $\mathrm{T}_{3}$ stages seeding one after another. Then precipitation distribution at 2200 displays that rainfall increased remarkably in the southwest, especially near the operation sites and their leeward sides. The rain belt extended to the north and east and tended to connected with that far belt impending from north-northeast.

The 10 sites continued implementing $\mathrm{T}_{4}$ and $\mathrm{T}_{5}$ stages operation by launching many rockets at about 2200 . Rainfall distribution at 2230 shows the precipitation core in the southwest separated into two after the large scaled operation at this two stages. They were along southwest and northeast direction and lied in west side of those operation sites in Fangshan and at the border of Mentougou-Shijingshan districts respectively, both with a maximum rainfall less than $1 \mathrm{~mm}$. Thereafter, operation sites in eastern Fangshan continued to seed the clouds during their moving to east. Precipitation in the southwest stopped till 2300, while the rain belt in the north kept stronger during its moving toward northeast.

\subsection{Precipitation Change of AWS}

Change of the 30-minute accumulated rainfall from Zhangfang, Yuegezhuang, Zhoukoudian and Tuoli stations in Fangshan district in Figure 6 show precipitation was observed in sequence along the direction of southwest to northeast. The rain almost ended after 2300. Corresponding to the wide distribution of the rain belt and its approximation to the city zone in Figure 5, the 30-minute rainfall at Zhoukoudian station accumulated up to $13 \mathrm{~mm}$ between 2130 and 2200, which is greater than its windward side stations such as Zhangfang and Yuegezhuang. It suggests convective clouds from southwest were strengthening during their moving.

Combining changes of intensive rainfall at Yuegezhuang and Zhoukoudian stations in Figure 7 and the seeding information from related sites S4 and S5, it is found that after rocket seeding at $\mathrm{T}_{-2}, \mathrm{~T}_{-1}$ and $\mathrm{T}_{1}$ stages before 2045 , there were no precipitation at Yuegezhuang and Zhoukoudian stations.

At Yuegezhuang station, rain mainly fell down on 2045 - 2130 and 2210 2310. Basically, rainfall during the early stage was stronger and it lasted $45 \mathrm{mi}-$ nutes, while it is relative weak during the later stage with a lifetime nearly one hour. This station witnesses raining since 2045, and the amount of rainfall in 5 minutes (2045 - 2050) was $4.5 \mathrm{~mm}$. Adjacent to its west side, site S4 carried out 


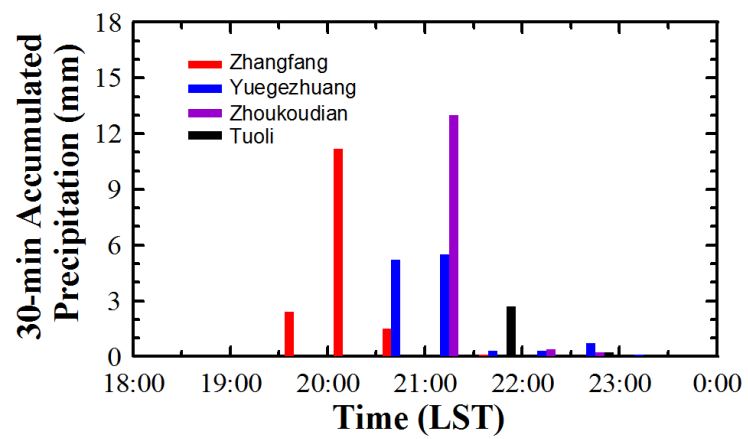

(a)

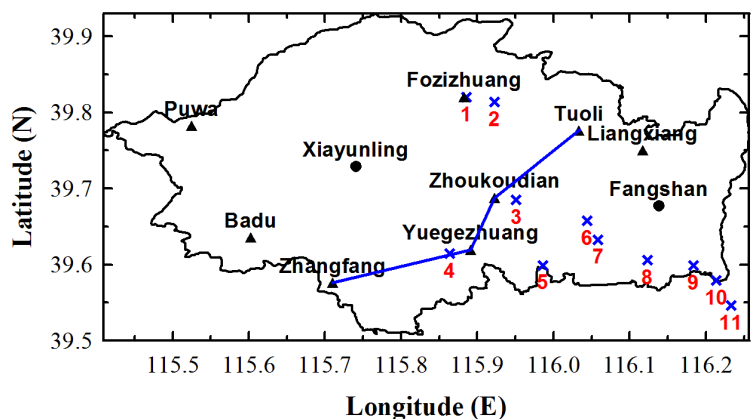

(b)

Figure 6. Time series of 30-min accumulated precipitation (a) at four automatic weather stations and their distribution (b) (4 stations in blue lines) in Fangshan district from 1800, 8 Aug. to 0000,9 Aug.

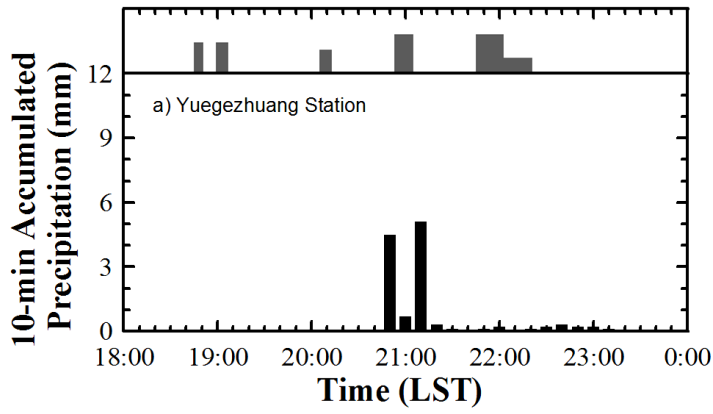

(a)

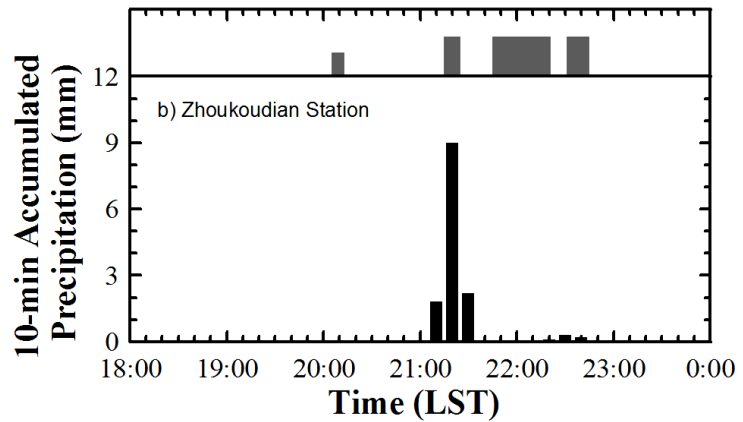

(b)

Figure 7. Time series of 10-min accumulated precipitation at Yuegezhuang station (a) and Zhoukoudian station (b) from 1800, 8 Aug. to 0000, 9 Aug., together with the seeding duration and relative intensity (top bar, using rocket numbers at different seeding time stages reflects its seeding intensity). 
$\mathrm{T}_{2}$ stage (2053 - 2105) seeding by launched 15 rockets in 12 minutes. The 10 minute rainfall between 2050 and 2100 rapidly reduced to $0.7 \mathrm{~mm}$. After 2100 rainfall observed at the same station enhanced significantly and accumulated to $4 \mathrm{~mm}$ in 5 minutes (2100 - 2105) and up to $5.1 \mathrm{~mm}$ in 10 minutes (2100 - 2110). Based on the above change of rainfall, rocket seeding from $\mathrm{S} 4$ at time stage $\mathrm{T}_{2}$ perhaps leaded to precipitation mitigation in a short period of time (5 - $10 \mathrm{mi}$ nutes), however, further development of precipitation in later 10 - 20 minutes was promoted. After 2110 precipitation at Yuegezhuang station decreased gradually and paused till 2130.

Rainfall during the later stage at Yuegezhuang station was very weak. After 2220 precipitation increased slightly and accumulated to $0.3 \mathrm{~mm}$ in 10 minutes till 2240. At the time, operation site S4, which is in the west side adjacent to Yuegezhuang station implements continuous $\mathrm{T}_{4}$ and $\mathrm{T}_{5}$ stages seeding (2145 2220). Thus, the site S4 contributes crucially to precipitation increasing at its leeward side Yuegezhuang station.

Zhoukoudian station is near the center of Fangshan district, which is also located in launching ranges intersection zone of many operation sites. At this station, precipitation occurred later than the upstream Yuegezhuang station. There exist two continuous raining periods of 2105 - 2130 and 2215 - 2240, both with a lifetime of 25 minutes. At this station, the rain began after 2105 and accumulated to $1.8 \mathrm{~mm}$ in 5 minutes. In the subsequent, 5 minutes $(2110-2115)$ precipitation increased rapidly and the amount is up to $6.1 \mathrm{~mm}$. Since 2115 , S3 and S5 carried out $\mathrm{T}_{5}$ stage operation and by each stage launched 15 rockets in 10 minutes. According the observation, precipitation at this station mitigated rapidly since 2115 and accumulated to $2.9 \mathrm{~mm}$ in 5 minutes from 2115 to 2120 . The rain stopped at 2130. Presumably, rocket seeding by S3 and S5 might have certain relations with precipitation mitigation during the same period at Zhoukoudian station.

\section{Change of Radar Reflectivity}

\subsection{Evolution of Radar Echo Images}

In the late afternoon of 8 August, convective clouds moving from the west was detected by CINRAD. Beijing suburbs gradually were covered by clouds and precipitation from the southwest and northeast. At 1600, clouds approached to the border line already. Figure 8 displays radar reflectivity CAPPI evolution at an elevation of $5 \mathrm{~km}$, a level that can be directly influenced by the seeding catalysts. In Fangshan, convective cells were detected and strengthened at about 1830 (corresponding to short-term rainfall from Xiayunling station in Figure 5). After 1900, convective clouds in the southwest continued to developing and moving closer. At the same time a strong convective cell observed in southern Huairou district was developing and strengthening. It seems that precipitable clouds coming from the above two directions will enclose the city zone at 2048. Thunder and lightning appeared over Miyun district.

After 2100, during convective clouds moving from southwest to northeast, the rear part kept stronger, while the front part tended to weaken. In addition, a 


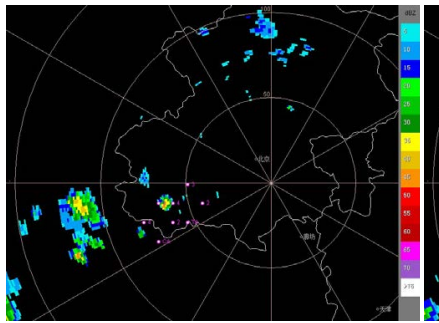

1824

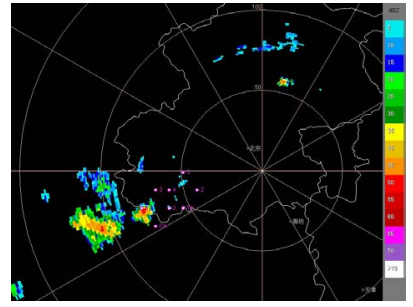

1912

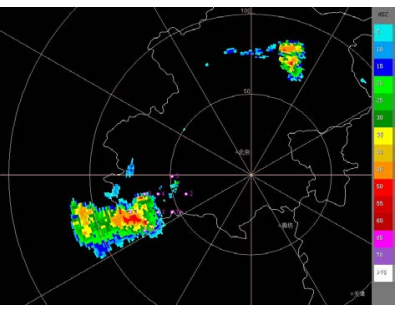

2000

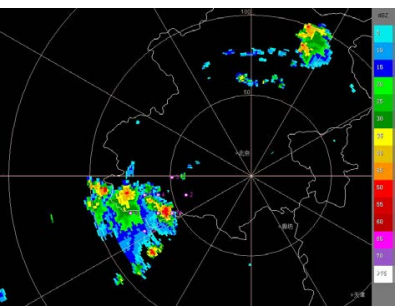

2048

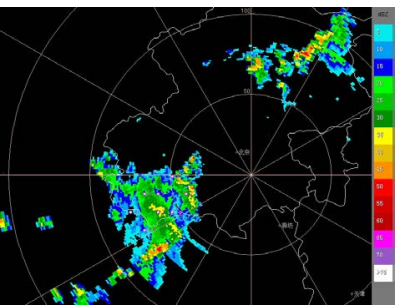

2136

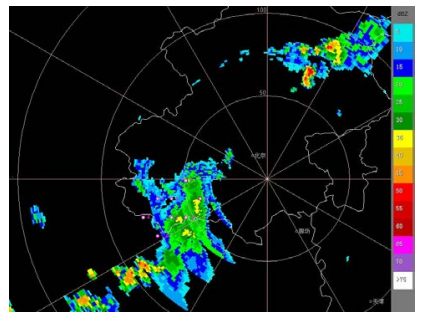

2224

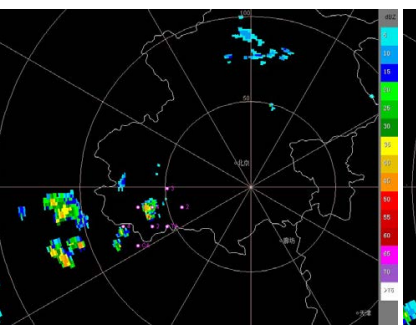

1836

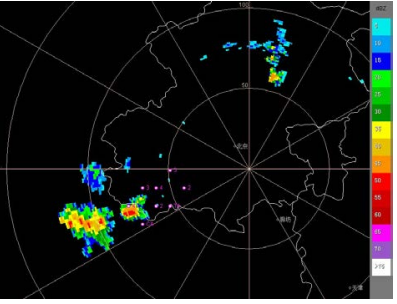

1924

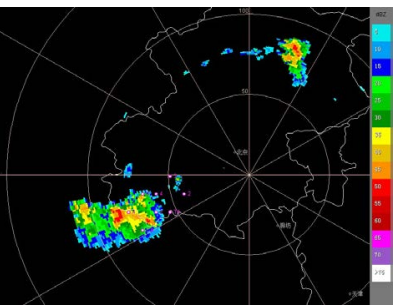

2012

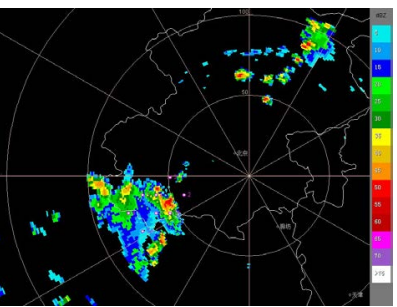

2100

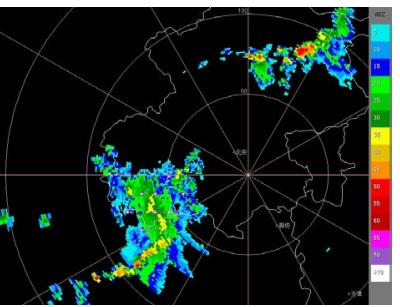

2148

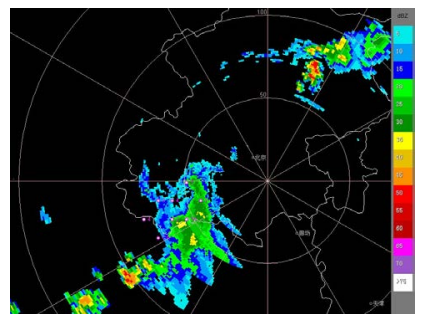

2236

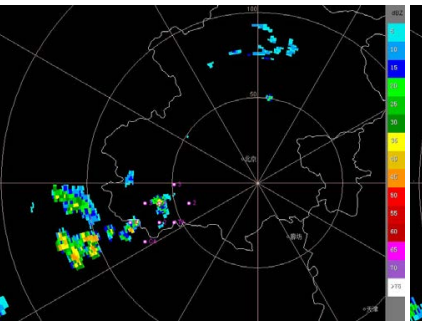

1848

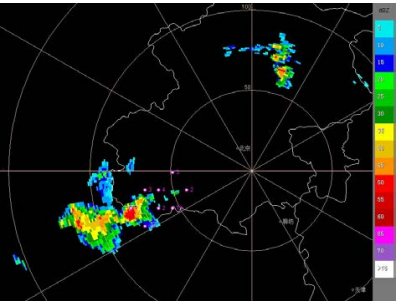

1936

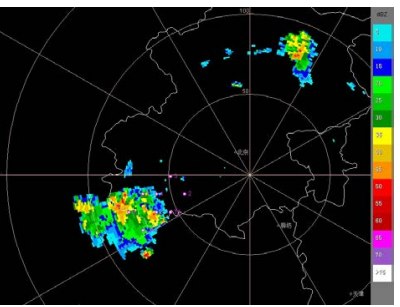

2024

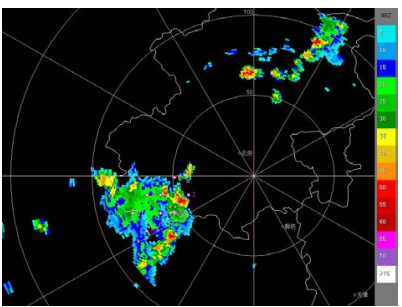

2112

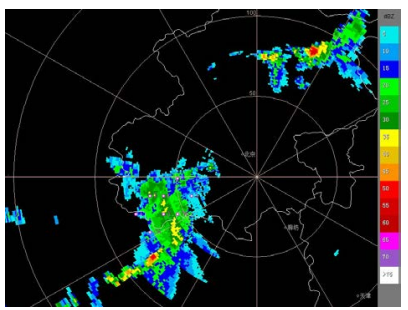

2200

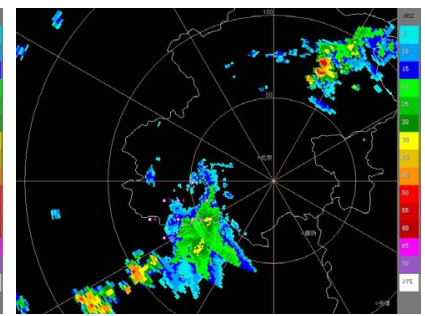

2248

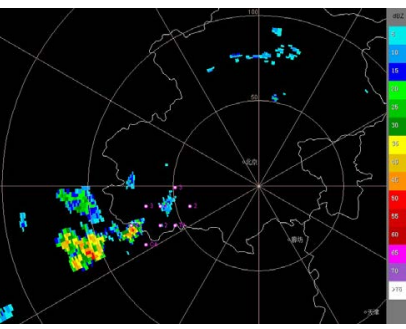

1900

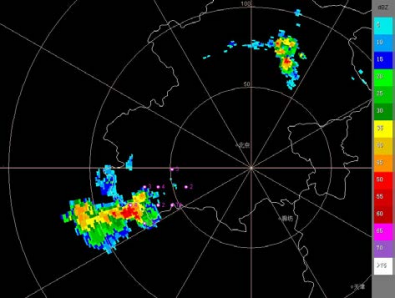

1948

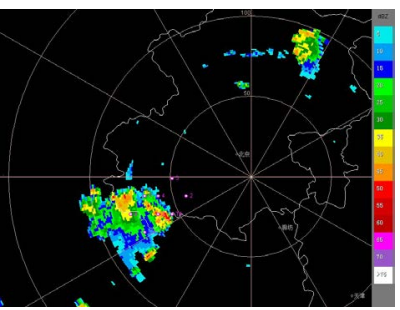

2036

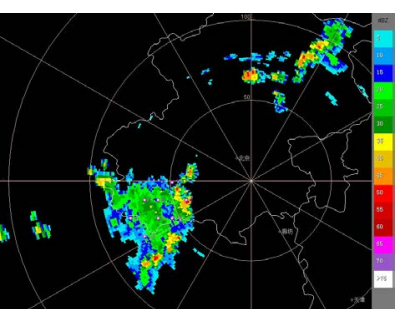

2124

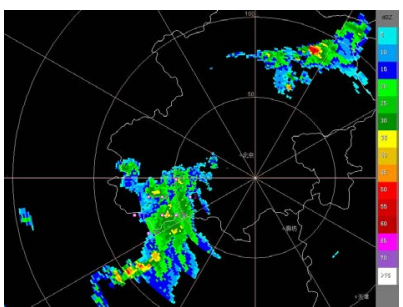

2212

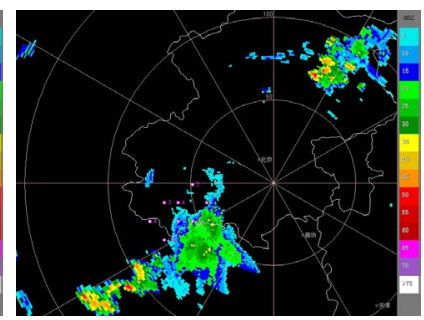

2300

Figure 8. Radar reflectivity CAPPI at $5 \mathrm{~km}$ level from 1824 to 23008 Aug. 
small developing cloud near the northeast side of its main body was detected and extended to north. For this reason, surface precipitation was impending to the city zone gradually. At 2130, the main body of strong clouds remained stagnant within Fangshan district and the front part continued to weaken. After 2200, the main body began to shift to southeast and moved gradually out of Beijing. Compared with precipitation clouds in the southwest, convective clouds in the northeast kept stronger during their slowly shifting to east and north. The moving direction and speed were similar with that in the southwest before 2130 .

\subsection{Local Features of Radar Echoes}

Based on ground-based operation sites, the high-level wind and radar echoes, a rhombus target area (TA in Figure 9) was selected near the leeward side of operation sites in the southwest to analyze possible physical response of clouds and precipitation after cloud seeding. Coordinates of the four peaks are $\left(116.0^{\circ} \mathrm{E}\right.$, $\left.39.6^{\circ} \mathrm{N}\right),\left(116.25^{\circ} \mathrm{E}, 39.75^{\circ} \mathrm{N}\right),\left(116.05^{\circ} \mathrm{E}, 39.95^{\circ} \mathrm{N}\right)$ and $\left(115.8^{\circ} \mathrm{E}, 39.8^{\circ} \mathrm{N}\right)$, respectively. Radar tracking indicates that isolated cells were appeared around 1748 in TA, but it lasted for a short time only. Extensive echoes were observed mainly after 2000. All clouds moved outside the area till 2330.

Convective clouds from southwest were moving to east and north. They entered the shooting range of operation site S4 (Yuegezhuangxi) at 2054. Rocket seeding was carried out immediately. This single site launched 15 rockets in total. Figure 10 displays strong echoes at the catalysts spraying level were not evidently modified after the operation.

After 2100, the main body of echoes gradually moved into the target area with a strong core close to $60 \mathrm{dBZ}$. Since 2115, S3 (Changgouzhen) and S5 (Zhoukou) implemented $\mathrm{T}_{3}$ stage operation. Between 2112 and 2130, area of echoes stronger than $30 \mathrm{dBZ}$ expanded, while the area and core of echoes stronger than $45 \mathrm{dBZ}$ shrank apparently. This is easily observed from the range of height indicator (omitted here) that height of the strong echo core, especially adjacent S3, lowers gradually. On the other hand, the intensity of that small isolated cloud close to the northeast side of the convective main body was not changed very much.

In Figure 10, large scaled echoes were developing in the southwest far from the target area after 2118; echoes stronger than $30 \mathrm{dBZ}$ appeared and expanded gradually. But the strong core of convective clouds in the target area continued

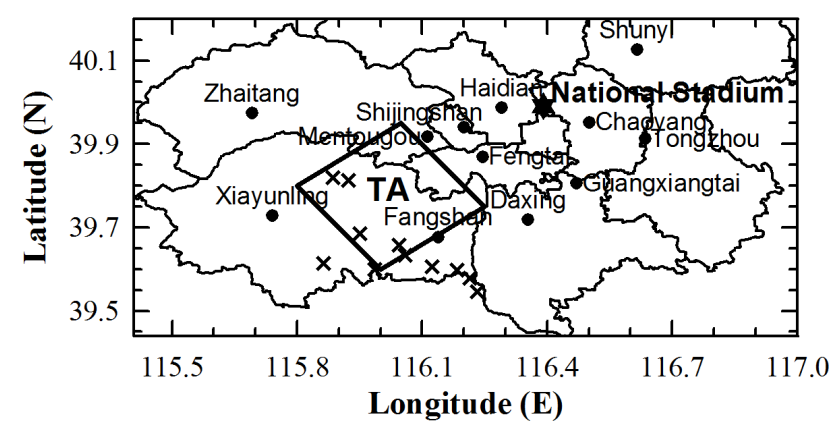

Figure 9. Distribution of ground-based operation sites and the selected target area. 

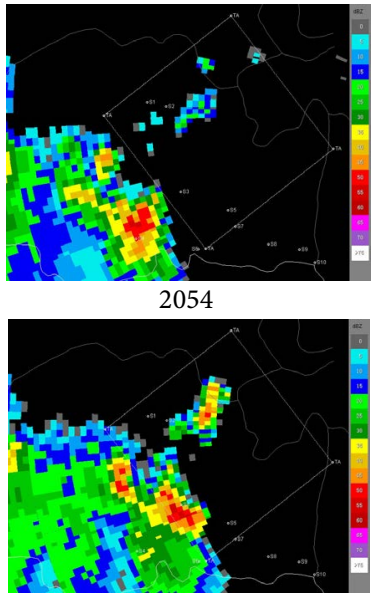

2112

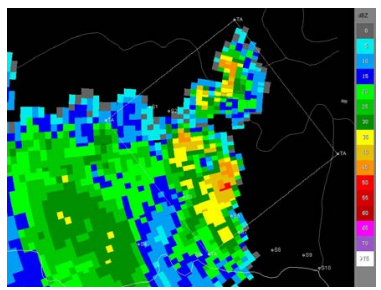

2130

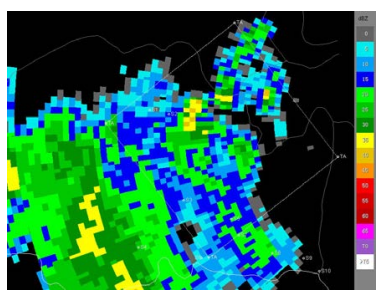

2148

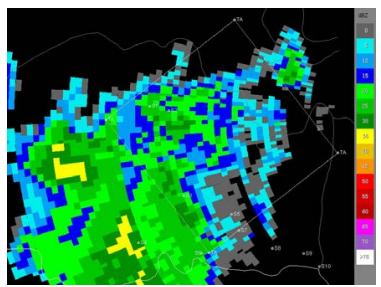

2206

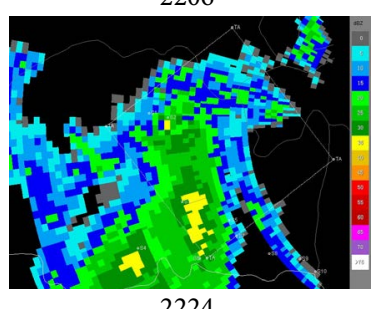

2224

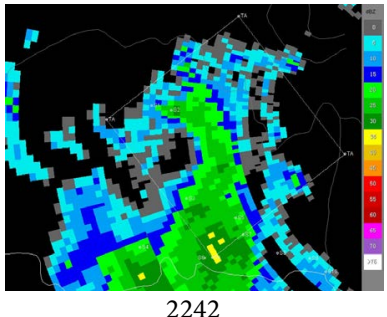

2242
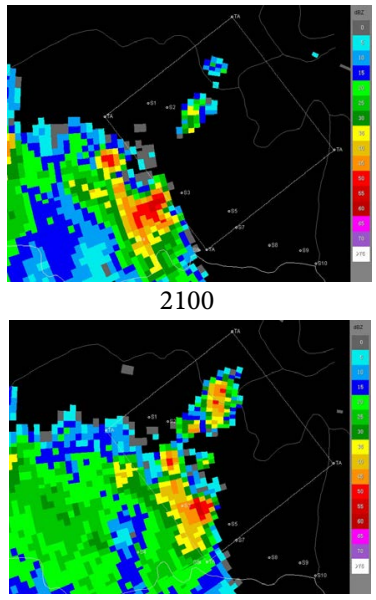

2118

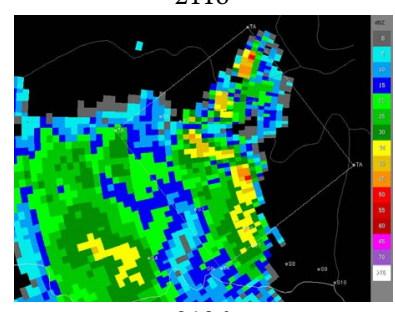

2136

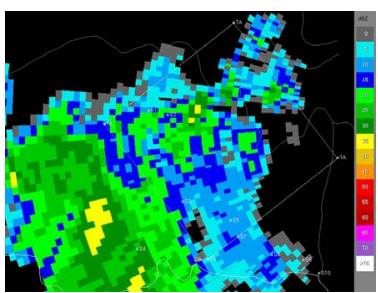

2154

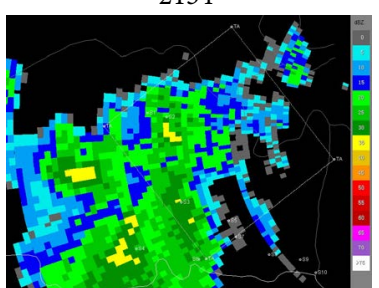

2212

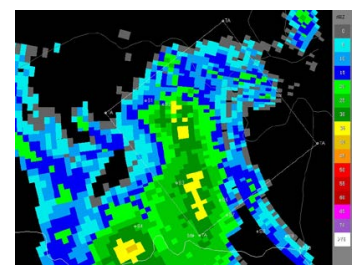

2230

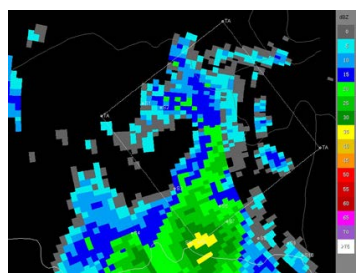

2248
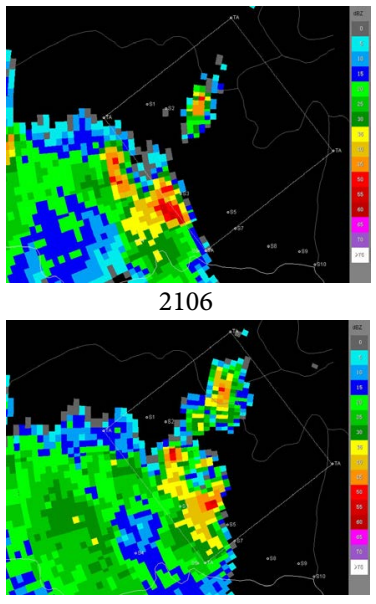

2124

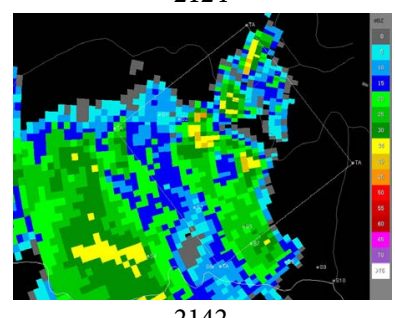
2142

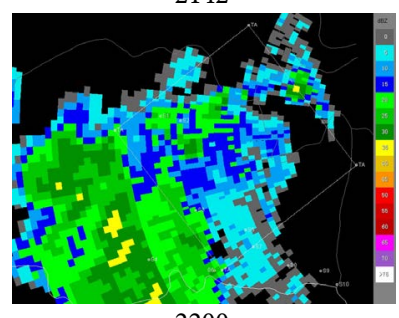

2200

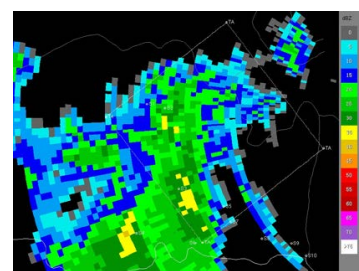

2218
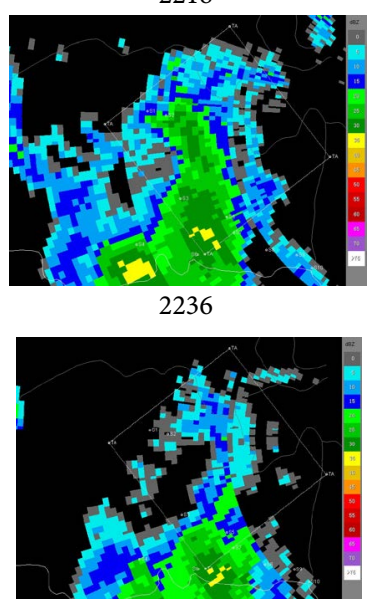

2254

Figure 10. Intensive radar reflectivity CAPPI at $5 \mathrm{~km}$ from 2054 to 22548 Aug. 
to shrink and reduced considerably after 2130 , even got discrete at 2142 . Till 2200 , since echoes intensity has already weakened less than $30 \mathrm{dBZ}$, the cloud main body got weak obviously. At that time, the 10 sites continued to perform $\mathrm{T}_{4}$ and $\mathrm{T}_{5}$ stages operation. Most of the sites shoot 30 rockets in 35 minutes. It is noted that, after 2206 clouds in the target area got a little stronger instead. Close to operation sites S1, S2, S3 and S5, the echoes stronger than $30 \mathrm{dBZ}$ developed again with their areas extending till 2230. Later, during its moving toward east, the echoes main body contracted to south and weakened gradually, and finally moved out of the target area.

\subsection{Statistics of Classified Radar Reflectivity}

Statistics of classified radar reflectivity factors on CAPPI at $5 \mathrm{~km}$ and $3 \mathrm{~km}$ levels together with the composite reflectivity (CR) are introduced to identify the evolution of convective clouds and its possible change after cloud seeding. The $5 \mathrm{~km}$ level is catalysts spraying, spreading and influencing height (according to Figure 3 ). Radar reflectivity at $3 \mathrm{~km}$ level can be used to simply mirror the surface precipitation.

In Figure 11, in the target area, most of the maximum CR at each time was stronger than $60 \mathrm{dBZ}$, with an extreme value of $67.5 \mathrm{dBZ}$ occurring at 2124. It suggests there were developing vigorous clouds in the target area. The maximum CR both at $5 \mathrm{~km}$ and $3 \mathrm{~km}$ levels changed remarkably with time, and their changing trend was relatively consistent. Difference of maximum CR between the two levels was slight at most times except for before 2100 and after 2200. It is shown in Figure 10 that before 2100 basically isolated thin clouds with fast developing and dissipation was existed in the target area. The change was much apparent around 2030 in Figure 11. At that time, clouds were very weak, since the maximum reflectivity at $3 \mathrm{~km}$ level was only $20 \mathrm{dBZ}$ and $4 \mathrm{dBZ}$ at $5 \mathrm{~km}$ level. Between 2100 and 2200 the maximum CR at $5 \mathrm{~km}$ level was very similar to that at $3 \mathrm{~km}$. Before 2118, the maximum CR at the low level $3 \mathrm{~km}$ was developing with an extreme intensity of $58 \mathrm{dBZ}$. While at the high level $5 \mathrm{~km}$, the maximum

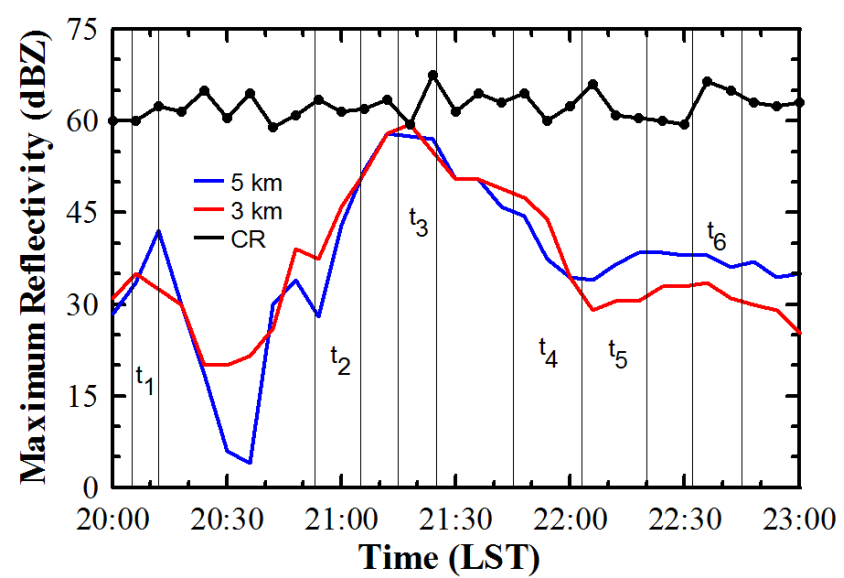

Figure 11. Maximum radar reflectivity at $5 \mathrm{~km}$ (blue), $3 \mathrm{~km}$ (red) and CR (black) from 2000 to 23008 Aug. 
CR began to decrease after 2112. Then they both decreased and the clouds got weakening. After 2200, clouds were developed again and maximum CR both at the high and low levels was increased, but their overall intensity was weaker than previous stage. This change agrees very well with what is showed in Figure 10.

At $5 \mathrm{~km}$ level in Figure 12, it is easy to find that areas of different classified radar echoes were extending and consequently clouds developed after the main body entered the target area at 2100. Area of strong echoes with $45-60 \mathrm{dBZ}$ continued to increase. After 2112, its area increased slowly, and then extended to its maximum coverage area of $34.16 \mathrm{~km}^{2}$ (about $4.5 \%$ of the target area) at 2118 . Later it began to decrease till to $0.75 \mathrm{~km}^{2}$ at 2142 , and then diminished. Variation of strong echoes area is exactly as same as that images change in Figure 10.

Ground-based sites S3 and S5 carried out $\mathrm{T}_{3}$ stage operation since 2115 and the seeding lasted 10 minutes. Compared with radar echoes over them, it can easily find that the dominant echo intensity near S5 was less than $30 \mathrm{dBZ}$, and S3 was straightly facing the strong core. Based on this, we infer that S3 probably has inhibited the development of the cloud core by launching 15 rockets. On the other hand, contraction and weakening of strong echoes of $45-60 \mathrm{dBZ}$ around the core in turn contribute to the area increasing of echoes weaker than $45 \mathrm{dBZ}$. Among of them, area of $30-45 \mathrm{dBZ}$ extended to a maximum coverage of 144.18 $\mathrm{km}^{2}$ firstly (about $18.9 \%$ of TA) at 2130 , area of $15-30 \mathrm{dBZ}$ extended to a maximum coverage of $297.68 \mathrm{~km}^{2}$ (about $39 \%$ of TA) at 2148 , and area of $0-15 \mathrm{dBZ}$ continued to increase till 2200 with a maximum coverage of $306.08 \mathrm{~km}^{2}$ (about $40.1 \%$ of TA) finally.

Similar to radar images change in Figure 10, areas of several echoes stronger than $15 \mathrm{dBZ}$ in TA had been reduced to their minimum till 2200 at $5 \mathrm{~km}$ level.
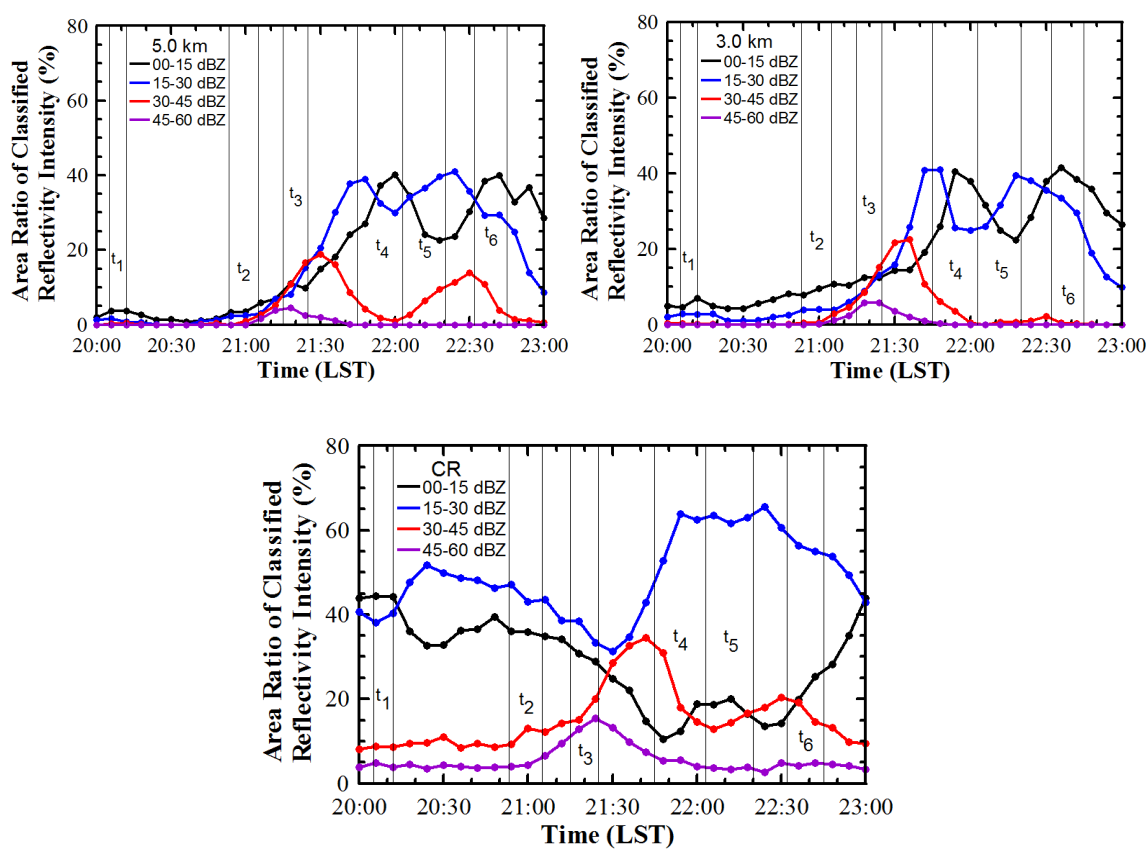

Figure 12. Time series of the ratios of classified radar reflectivity at $5 \mathrm{~km}, 3 \mathrm{~km}$ and CR from 2000 to 23008 Aug. 
The cloud main body was very weak at that time and only echoes weaker than 30 $\mathrm{dBZ}$ was existed, which is generally unfavorable to precipitation. As shown in Figure 12, following with the 10 sites operation at continuous time stages of $\mathrm{T}_{4}$ and $\mathrm{T}_{5}$, coverage areas of $15-30 \mathrm{dBZ}$ and $30-45 \mathrm{dBZ}$ at $5 \mathrm{~km}$ level were expanding again from 2200 to about 2230. This shows rocket seeding at this two time stages perhaps plays an important role in the second-time development of clouds. After 2230, areas of above two echoes intensity began to decrease, consequently the clouds got weakening. Rocket seeding at $\mathrm{T}_{6}$ and later stages hastened the mitigation.

Area change of $0-15 \mathrm{dBZ}$ is similar to that of $15-30 \mathrm{dBZ}$ in Figure 12 except that the peak time of $0-15 \mathrm{dBZ}$ area occurred 12 - 18 minutes later than the 15 $30 \mathrm{dBZ}$. In general, the coverage area of 15 - $30 \mathrm{dBZ}$ decreased firstly followed with an increase, due to the transition between strong echoes and weak ones. After 2230, coverage areas of all echoes ranks began to decrease along with the weakening and dissipation of the clouds.

At $3 \mathrm{~km}$ level in the target area, area of each echoes rank changed consistent with that at $5 \mathrm{~km}$ level. They both have peak area and peak times between the high and low levels appear very close too. The first peak area at the low $3 \mathrm{~km}$ level was greater than that same rank at $5 \mathrm{~km}$ level, mainly due to the vertical shifting of echoes. The obvious discrepancy between the two levels happened at 2230 , the second peak area of perceptible echoes of $30-45 \mathrm{dBZ}$ at the low level (17.05 $\mathrm{km}^{2}$ and $\left.13.9 \%\right)$ was far less than that at $5 \mathrm{~km}\left(105.82 \mathrm{~km}^{2}\right.$ and $\left.2.2 \%\right)$ around that time. This contributes very much to the mitigation of surface precipitation.

Change of the composite reflectivity in the target area shows that echoes area of 45 - $60 \mathrm{dBZ}$ reached its peak coverage at 2130 with a tiny increase around 2230. There are two evident peak areas of $30-45 \mathrm{dBZ}$ after 2100 . One occurred at 2142 and the other occurred at 2230 respectively. Echoes area of $15-30 \mathrm{dBZ}$ covered most of the target area between 2154 and 2230, which was due to the clouds developing. On the other hand, it has a relation with the transition of much stronger echoes. At that time, weaker echoes of 0 - $15 \mathrm{dBZ}$ maintained a small coverage and taken an opposite change. Peak coverage of every echoes rank in TA appeared one by one following with the clouds moving. The first peak time of 45 - $60 \mathrm{dBZ}, 30$ - $45 \mathrm{dBZ}, 15$ - $30 \mathrm{dBZ}$ and 0 - $15 \mathrm{dBZ}$ were at 2124, 2142,2154 and 2212 respectively, and the interval lasted about two or three volume scan period (12 - 18 minutes).

Integrated echoes coverage ratios at $5 \mathrm{~km}, 3 \mathrm{~km}$ and CR levels, it is found the first peak area of $30-45 \mathrm{dBZ}$ which was favorable for precipitation increased from low to high, while the second peak area decreased. This is just the result of early developing and late gradually settling down of the clouds echoes.

\section{Conclusions and Discussion}

Based on radar reflectivity and rainfall data at relatively higher spatial and temporal resolutions, some physical responses of convective cloud seeding with 
rockets in southwestern Beijing on the opening day of the 2008 Summer Olympics are analyzed. It was obtained:

1) Before the opening ceremony starting time (2000), precipitation occurred mainly in the west side of Fangshan district. After $\mathrm{T}_{-2}(1845-1851)$ and $\mathrm{T}_{-1}(1859$ - 1906) stages seeding at the operation site S4 (Yuegezhuangxi), no precipitation was observed near the site and its leeward side. With the development and north stretch of clouds and precipitation, 10 operation sites in Fangshan carried out $\mathrm{T}_{1}$ (2005 - 2012) stage rocket seeding; rainfall was rarely observed in the concentrated area of those operation sites.

2) Rocket seeding by single operation site $S 4$ at $T_{2}(2053$ - 2105) stage, might attribute to precipitation mitigation at its leeward side station Zhoukoudian in a short period of time (5 - $10 \mathrm{~min}$ ), but it promoted the precipitation strengthening in the later 10 - 20 minutes. Local change of strong echoes in 6-minute intervals at the seeding agents spreading level was not apparent.

3) Operation sites $\mathrm{S} 3$ (Changgouzhen) and $\mathrm{S} 5$ (Zhoukou) carried out $\mathrm{T}_{3}(2115$ - 2125) stage rocket seeding after strong echoes entered the target area. Precipitation observed at Zhoukoudian, a station very close to S3, decreased rapidly. During this period, intensity of the echoes core and coverage area of $45-60 \mathrm{dBZ}$ over S3 mitigated and contracted remarkably, followed by a decreasing reflectivity extreme, while echoes area of $30-45 \mathrm{dBZ}$ extended.

4) During the late period when echoes were getting weak in the target area, 10 operation sites implemented $\mathrm{T}_{4}\left(2145\right.$ - 2203) and $\mathrm{T}_{5}(2203$ - 2220) stages rocket seeding. Echoes intensity over S1 (Fozizhuang), S2 (Hebeizhen), S3 (Changgouzhen) and S5 (Zhoukou) enhanced stronger than $30 \mathrm{dBZ}$. Echoes areas of 15 - $30 \mathrm{dBZ}$ and 30 - $45 \mathrm{dBZ}$ both expanded. Rocket seeding by the operation site S4 in the west side of the target area might promote the increasing of precipitation at neighboring and its leeward side Yuegezhuang station.

5) At about 2230, precipitation intensity in Fangshan district mitigated remarkably. The rain belt separated along south-west and north-east direction and was divided into two. Many operation sites in the east side of Fangshan carried out $\mathrm{T}_{6}(2232-2245)$ and $\mathrm{T}_{7}(2258$ - 2310) stages rocket seeding. Almost no precipitation was observed near the operation sites and their leeward sides.

According to radar detection and AWS observation, clouds over many operation sites in the east side of Fangshan district were not very strong and cold all the time, and sometimes even unfavorable for glaciogenic seeding with AgI. Seeding effects on clouds and precipitation by operation sites S4 (Yuegezhuangxi), S3 (Changgouzhen) and S5 (Zhoukou), which are located in the west side and near the center of Fangshan (also lie in the main route of strong echoes), are quite conspicuous. Combining the sites position with radar echoes intensity, it was found that operation site S3 was exactly facing to the strong core of convective clouds; its operation seeding played a crucial role in suppressing the development of the strong core and contracting echoes area of $45-60 \mathrm{dBZ}$ in particular.

In addition, large scale rocket seeding shall deliver and spread into clouds 
much silver iodide flame with high nucleation rate. They can participate into the formation and growth of clouds and precipitation, and help to change surface precipitation. On the other hand, lots of rockets seeded in such a short period of time may readily stir vertical or horizontal airflow inside clouds. That kind of dynamic effect on clouds is rather drastic (Huang [21]; Xu et al. [22]; Zhou et al. [23]). Clearly, further research and exploration on these uncertainties from cloud seeding are needed in the future.

\section{Acknowledgements}

The authors thank associate researcher Chunyi Xuan for providing the AWS data and Jianli Ma for providing the radar code for reference. This work was founded by the Beijing Key Laboratory of Cloud \& Precipitation Physics Research and Cloud Water Exploitation.

\section{References}

[1] Schaefer, V.J. (1946) The Production of Ice Crystals in a Cloud of Supercooled Water Droplets. Science, 104, 457-459. https://doi.org/10.1126/science.104.2707.457

[2] Huang, M., Shen, Z. and Hong, Y. (2003) Advance of Research on Cloud and Precipitation and Weather Modification in the Latest Half Century. Chinese Journal of Atmospheric Sciences, 27, 536-551. (In Chinese)

[3] Lei, H., Hong, Y., Zhao, Z., Xiao, H. and Guo, X. (2008) Advances in Cloud and Precipitation Physics and Weather Modification in Recent Years. Chinese Journal of Atmospheric Sciences, 32, 967-974. (In Chinese)

[4] Zhang, J., Su, Z., Guan, L., Huang, G. and Shi, A. (2005) Study and Ideas of Some Front Scientific Issues on Weather Modification. Proceedings of the 14th Chinese Scientific Conference on Cloud and Precipitation Physics and Weather Modification, Guiyang, Chinese Meteorological Society, 753-754.

[5] Ye, J. (1993) On the Possibility of Artificial Suppression of Heavy Rains. Journal of Nanjing Institute of Meteorology, 16, 373-378. (In Chinese)

[6] Li, D., Zhang, C., Xu, H., et al. (2002) The Status and Development Prospects of Weather Modification. Meteorological Press, 586 p. (In Chinese)

[7] Bedritsky, A.I. and Chernikov, A.A. (1996) Cloud Seeding to Protect Moscow from Rain on 9 May 1995. World Meteorological Organization Bulletin, 45, 60-64.

[8] Petrov, V., et al. (1998) “95.5.9” Cloud Dispersal and Rain Mitigation Experiments with Multi-Aircrafts in Moscow City (Translated into Chinese). Xinjiang Meteorology, 21, 44-47. (In Chinese)

[9] Korneev, V.P., Petrov, V.V., Diadyuchenko, V.N., et al. (2003) Results of Cloud Seeding Operations to Modify Weather Conditions over Cities. Proceedings of the 8 th WMO Scientific Conference on Weather Modification, Casablanca, Morocco, WMO/TD-No. 1146, 227-230.

[10] Koloskov, B.P., Korneev, V.P., Petrov, V.V., et al. (2007) Cloud Seeding Operations to Modify Weather Conditions over Cities: 2003-2006. Proceedings of the 9 th WMO Scientific Conference on Weather Modification, Antalia, Turkey, WMP-No. 44.

[11] Petrov, V.V., Egorov, O.G., Melnik, S.V., Zakharov, A.M. and Skuratov, S.N. (2007) "Land-Aircraft-Land" Data Transmission System. Proceedings of the 9th WMO Scientific Conference on Weather Modification, Antalia, Turkey, WMP-No. 44. 
[12] Zhu, Y., Chen, Y., Li, Q. and Xiong, A. (2006) Preliminary Analysis on Meteorological Conditions during 2008 Beijing Olympic Games. Journal of Applied Meteorological Science, 17, 35-41. (In Chinese)

[13] Zhang, Q., He, H., Liu, J., et al. (2009) Brief Introduction of Rain Mitigation Operation during Beijing 2008 Olympic Opening Ceremony. Meteorological Monthly, 35, 3-15. (In Chinese)

[14] Zhang, Q., He, H., Huang, M., et al. (2011) Brief Introduction of the Rain Mitigation Operations during Beijing 2008 Olympic Opening Ceremony. 18th Conference on Planned and Inadvertent Weather Modification, Seattle, Extended Abstracts Volume, Washington, American Meteorological Society. https://ams.confex.com/ams/91Annual/webprogram/Paper178055.html

[15] Li, H., Zhou, W. and Zhou, Y. (2008) Change of Satellite Retrieving Cloud Parameters during Artificial Rain Mitigation Operation. Meteorological Monthly, 34, 136140. (In Chinese)

[16] He, H. and Ma, J. (2008) The Comprehensive Analysis of the Characteristics of Radar Echo during Artificial Rain Mitigation Operation. Meteorological Monthly, 34, 145-149. (In Chinese)

[17] Li, H., Ma, J., Ma, Y. and Tao, Y. (2011) Characteristics of Cloud-Precipitation and the Impact of Weather Modification Activities on the Opening Day of the Beijing 2008 Olympics. Climatic and Environmental Research, 16, 175-187. (In Chinese)

[18] He, H., Jin, H., Li, H. and Liu, J. (2012) Preliminary Study of the Mesoscale Numerical Simulation of the Rain Mitigation Operation during the Opening Ceremony of the 2008 Beijing Olympic Games. Climatic and Environmental Research, 17, 46-58. (In Chinese)

[19] Dong, L., Zhang, M., Guo, H. and Zhou, Q. (2008) Preliminary Analysis on Weather Forecasting Difficulties during the Opening Ceremony of 2008 Beijing Olympic Games. Meteorological Monthly, 34, 9-15. (In Chinese)

[20] Rokicki, M.L. and Young, K.C. (1978) The Initiation of Precipitation in Updrafts. Journal of Applied Meteorology, 17, 745-754. https://doi.org/10.1175/1520-0450(1978)017<0745:TIOPIU>2.0.CO;2

[21] Huang, M., Xu, H., Wang, A., et al. (1979) Studies of Influence on Development of Convective Clouds by Explosion. Chinese Journal of Atmospheric Sciences, 3, 280 288. (In Chinese)

[22] Xu, H., Huang, M., Hao, J., et al. (1986) Numerical Study of Artificial Effects on Cumulus Clouds Macroscopic Dynamic. Proceedings of Cloud Physics and Weather Modification in South China, The Edit Group, Meteorological Press, 121-124. (In Chinese)

[23] Zhou, F., Xiao, H. and Huang, M. (2005) Modeling Evaluation of Effects of Artificial Updraft Restraints in a Strong Hailstorm on Its Precipitation. Journal of Nanjing Institute of Meteorology, 28, 153-162. (In Chinese) 
Submit or recommend next manuscript to SCIRP and we will provide best service for you:

Accepting pre-submission inquiries through Email, Facebook, LinkedIn, Twitter, etc. A wide selection of journals (inclusive of 9 subjects, more than 200 journals)

Providing 24-hour high-quality service

User-friendly online submission system

Fair and swift peer-review system

Efficient typesetting and proofreading procedure

Display of the result of downloads and visits, as well as the number of cited articles Maximum dissemination of your research work

Submit your manuscript at: http://papersubmission.scirp.org/

Or contact gep@scirp.org 